\title{
Are Complex Demonstratives Synonymous with Definite Descriptions? ${ }^{1}$
}

São os demonstrativos complexos sinônimos de descrições definidas?

\author{
Felipe S. Amaral \\ Universidade de Brasília
}

\begin{abstract}
In this article, I discuss the way in which descriptive material in complex demonstratives contributes to their literal content relative to the context of the utterance. A traditional hypothesis about complex demonstratives in the philosophy of language postulates that the descriptive material ' $F$ ' in 'this/that F' contributes to literal content because an associated definite description containing ' $\mathrm{F}$ ' determines and expresses the literal content of the complex demonstrative relative to a context. I claim that this kind of hypothesis is mistaken because no type of definite description, particularly Gödelian descriptions, plays a significant role in the determination of the literal content of complex demonstratives. Instead, I favor an approach according to which the literal content of a complex demonstrative is mainly composed by the nonquantificational content of the demonstrative expression (e.g., 'this'), and by the descriptive content of its nominal ('F'). Complex demonstratives are thus descriptive designators, that is, terms that refer and describe without quantifying.
\end{abstract}

Keywords

Complex demonstratives; definite descriptions; description theory of demonstratives; Gödelian theory; descriptive designators. 


\section{Resumo}

Neste artigo, discuto como o material descritivo dos demonstrativos complexos contribuipara o seu conteúdo literal relativo a um contexto de proferimento. Em filosofia da linguagem, uma hipótese tradicional sobre os demonstrativos complexos prevê que o material descritivo ' $F$ ' de um demonstrativo complexo faz uma contribuição ao conteúdo literal porque uma descrição definida contendo o nominal ' $\mathrm{F}$ ' determina e expressa o conteúdo literal do demonstrativo complexo relativo ao contexto de proferimento. Assevero que este tipo de hipótese envolve erro porque nenhum tipo de descrição definida, descrições Gödelianas em particular, tem papel efetivo na determinação do conteúdo literal dos demonstrativos complexos. Em vez disso, sou favorável a uma abordagem segundo a qual o conteúdo literal de um demonstrativo complexo é exaustivamente composto pelo conteúdo nãoquantificacional da expressão demonstrativa (e.g., 'esta') e pelo conteúdo descritivo de seu nominal (e.g., 'mesa'). Demonstrativos complexos são, portanto, designadores descritivos, termos que se referem e descrevem sem quantificar.

\section{Palavras-chave}

Demonstrativos complexos; descrições definidas; teoria descritivista dos demonstrativos; teoria Gödeliana; designadores descritivos. 


\section{Introduction}

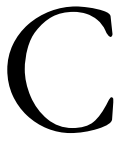

omplex demonstratives in English are expressions of the form 'this F' or 'that $\mathrm{F}$ ', where ' $\mathrm{F}$ ', the nominal of the demonstrative, is a common noun possibly modified by other expressions such as adjectives, prepositional phrases or restrictive relative clauses (e.g. 'that woman', 'that tall woman', 'that tall woman with glasses', 'that tall woman with glasses looking in your direction'). Bare demonstratives contrast with complex demonstratives by lacking a nominal. 'This' and 'that' are bare demonstratives in English. ${ }^{2}$

Much of the debate around the semantics of complex demonstratives has centered on the issue of whether nominals make a semantic contribution. On the assumption that they do, the question becomes what kind of contribution this is. In the wake of influential work by David Kaplan (1989), this question has been approached from two complementary perspectives: nominals may contribute to reference determination and they may contribute to literal content. ${ }^{3}$ In the former perspective, nominals constitute a condition of successful reference; if the intended referent does not fit the nominal, it cannot be referred to by the complex demonstrative token, relative to the context of utterance. In the latter perspective, nominals constitute a condition of truth and falsity; if the referent does not fit the nominal, the expressed literal content is false, if apt for truth.

Those who think that nominals contribute to reference determination have only conquered important new ground in the past few years (v. SALMON, 2008; BRAUN, 2008). Yet, I still think that nominals contribute both to reference determination and literal content. One very good reason is that this hypothesis affords what appears to be the best explanation for the intuitive validity of arguments like 'if that violinist is a conductor $\backslash$ some violinist is a conductor' (v. LEPORE; LUDWIG, 2000; cf. BORG, 2000).

Thus, my main concern in this essay lies not in whether nominals contribute to the literal content of complex demonstratives, but rather in how they might do this. A traditional way of understanding this contribution is via definite 
descriptions: 'F' contributes to the literal content of 'that F' because a definite description containing ' $F$ ' determines and expresses the literal content of 'that $F$ '. For example, 'table' contributes to the literal content of (a token of) 'that table' relative to a particular context of utterance because the definite description 'the table there' gives the literal content of 'that table' in that context.

I believe the contribution nominals make to the literal content of complex demonstratives is independent of any definite descriptions speakers may come to associate with them. And I think this because the literal content of complex demonstratives is not determined by associated descriptions of any sort. In my view, descriptions play no explanatory role in the literal content of complex demonstratives, so on methodological grounds we are better off without them.

Yet, to try to show this, I will take an indirect route. In section 2, I will summarize what I take to be the core constraints on all synonymy theories of complex demonstratives, those theories that entail that complex demonstratives are synonymous with definite descriptions. I will argue that only one such theory meets all of these constraints, namely the 'Gödelian theory', put forth by Ernest Lepore and Kirk Ludwig (2000) and Stephen Neale (2004, 2008b) (v. KING, 2001; cf. SOAMES, 2005). ${ }^{4}$ According to the Gödelian theory, 'that F' is synonymous with a Gödelian description 'the F identical to that', where 'that' picks out the object the speaker intends to refer to in uttering 'that $F$ ' in the context of the utterance. The upshot of this discussion will be that the Gödelian theory is the best synonymy theory of complex demonstratives. In section 3, I will turn to natural language syntax and ask the following question: on the hypothesis that complex demonstratives are synonymous with Gödelian descriptions, what syntax do they have? I will describe two strategies for an answer and urge that syntactic theory in the Principles and Parameters framework does not force us to choose either. ${ }^{5}$ The upshot of this discussion will be that we should cultivate a positive disposition towards complex demonstratives being what they seem to be at face value: non-quantificational terms that refer and describe. And, last, in section 4, I will develop a methodological argument that shows that the literal content of complex demonstratives is not determined by Gödelian descriptions. Since Gödelian descriptions are the only ones in the running among description theories, I will claim that the literal content of complex demonstratives is not determined by definite descriptions of any sort. I will end with a brief outline of what I believe complex demonstratives are from a semantic point of view. 
Thus, if I am right, explaining the contribution nominals make to the literal content of complex demonstratives does not involve recourse to associated descriptions. And this, coupled with the idea that definite descriptions are natural language quantifers (NEALE, 1990), implies something important to our understanding of natural language semantics: expressions in the singular standardly used to refer may have descriptive content without being quantificational. They are what I would call 'descriptive designators' (v. BURGE, 1974; RICHARD, 1993; DEVITT; STERELNY, 1999; DEVER, 2001; DEVITT, 2004 for implementations of this sort of view). ${ }^{6}$

But before starting, three preliminary points are in order. First, I will consider perceptual uses of complex demonstratives only, uses according to which the speaker intends to refer to a particular object he or she has in mind, an object that he or she perceives (and believes the audience to perceive) in the context of the utterance. I think my main conclusions apply to other referential uses too, but I am not going to argue for that point here.

Second, I will not discuss uses of complex demonstratives in which the speaker does not intend to refer to a particular object he or she has in mind, exemplified by sentences like 'those men who help others should be rewarded' (v. KING, 2001 for discussion of such uses). In what follows, my conclusions are meant to apply to referential uses only. One good reason for this restriction in the scope of my discussion is the promising idea that non-referential uses of complex demonstratives should receive an independent, non-referential semantics. ${ }^{8,9}$

And, third, following Saul Kripke (1980) it is customary to distinguish two types of description theory of a given term: a theory of 'reference determination' and a theory of 'meaning'. In this essay, I will focus on the second kind - 'synonymy theories', as I will call them. The main claims I will make apply to reference determination theories as well, though I will not argue for that point here.

\section{Synonymy Theories of Complex Demonstratives}

In the philosophical literature of the past forty years, synonymy theories of complex demonstratives have been assessed with respect to several dimensions, including methodological, modal, epistemic, semantic, psychological, and syntactic (v. e.g. BURGE, 1974; PERRY, 1977; SCHIFFER, 1981; HIGGINBOTHAM, 1988; KAPLAN, 1989, NEALE, 1993; RICHARD, 1993; BRAUN, 1994, SCHIFFER, 1995; BORG, 2000; LEPORE; LUDWIG, 2000; 
PERRY, 2001; KING, 2001; DEVER, 2001; SALMON, 2002; DEVITT, 2004; NEALE, 2004; SCHIFFER, 2005; NEALE, 2008a,b). In virtue of these assessments and in light of independently achieved results on the semantics of other terms, notably, proper names, incomplete definite descriptions, and pronouns, a list of constraints on synonymy theories of complex demonstratives is gradually coming into focus. The list I have in mind is not meant to be exhaustive - for example, it leaves out syntactic constraints - although I think it is fair to say that all, or at least most, of its members are necessary components of an exhaustive future version..$^{10}$ Here is the version I have in mind:

(1) A synonymy theory of complex demonstratives should be principled.

(2) The theory should not predict implausible ambiguities.

(3) It should not predict implausible indeterminacy.

(4) It should not predict implausible necessities.

(5) It should not predict implausible a priori knowledge.

(6) It should not predict implausible entailments.

(7) It should not ascribe implausible attitudes to speakers.

(8) It should not attribute implausible psychological associations to speakers.

In 2.1 , I will briefly describe these constraints. In 2.2 , I will assess synonymy theories in their light.

\subsection{The Constraints}

Constraint 1: 'Principled basis' (DEVITT, 2004; cf. SCHIFFER, 1995). Speakers often associate several definite descriptions with a complex demonstrative token. For example, 'that table' in 'that table is expensive' as uttered by me in a particular context may be associated with 'the table over there', 'the table next to June', or 'the table I intend to refer to now'. A synonymy theory of complex demonstratives should explain why one associated description, rather than another, is synonymous with the complex demonstrative.

Constraint 2: No implausible ambiguities (cf. SALMON, 2002; DEVITT, 2004). Our unreflective judgments about the literal content of complex demonstratives suggest that if the nominal of a complex demonstrative is not 
ambiguous, the complex demonstrative as a whole is not ambiguous either. Since we have no persuasive reasons to revise these judgments, a synonymy theory should preserve them.

Constraint 3: No implausible indeterminacy (cf. WETTSTEIN, 1981; SCHIFFER, 1995). Our unreflective judgments about the literal content of complex demonstratives also suggest that if the nominal of a complex demonstrative does not induce indeterminacy in literal content, the complex demonstrative as a whole is not indeterminate in literal content. Since we have no persuasive reasons to revise these judgments, a synonymy theory should preserve them.

Constraint 4: No implausible necessities (cf. KAPLAN, 1989, SOAMES, 2002). Our unreflective judgments about the literal content of sentences containing complex demonstratives suggest that when $\mathrm{f}$ is not an essential property of an object ${ }^{*}$ and the content of $\mathrm{f}$ is not part of the content of the nominal ' $\mathrm{F}$ ', a declarative utterance of 'that $\mathrm{F}$ is $\mathrm{f}$ ' with the demonstrative used to refer to ${ }^{*}$ does not have a necessary reading (e.g. 'that tomato is perceived by me now'). Since we have no persuasive reasons to revise these modal judgments, a synonymy theory should preserve them.

Constraint 5: No implausible a priori knowledge (cf. SOAMES, 2002). Our unreflective judgments about the literal content of complex demonstratives also suggest that when the content of $f$ is not part of the content of the nominal ' $F$ ' and $f$ is an empirical property, an utterance of 'if that $F$ exists, then that $F$ is $f$ ' is not knowable a priori (e.g. 'if that tomato exists, then that tomato is perceived by me now). ${ }^{11}$ Since we have no persuasive reasons to revise these epistemic judgments, a synonymy theory should preserve them.

Constraint 6: No implausible entailments (LEPORE; LUDWIG, 2000; cf. KAPLAN, 1989; PERRY, 2001). A synonymy theory of complex demonstratives should not predict implausible entailments from the literal content of complex demonstrative utterances. For example, it should not predict that from the literal content of an utterance of, say, 'that tree is dead' it semantically follows that the speaker of the demonstrative exists.

Constraint 7: No implausible attitude ascriptions (NEALE, 2008b; cf. SCHIFFER, 1995; SOAMES, 2002). A synonymy theory should not ascribe implausible propositional attitudes to speakers. For example, it is perfectly conceivable that someone in a counterfactual world believes the literal content of my utterance of, say, 'that river is polluted' without harboring any attitude 
whatsoever with respect to me or the actual world (my actual world). A synonymy theory should preserve these sorts of intuitions. ${ }^{12}$

Constraint 8: No implausible associations (PERRY, 1977; WILSON, 1991; DEVITT, 2004; SCHIFFER, 2005). A synonymy theory should not attribute associations between complex demonstratives and definite descriptions competent speakers do not (or could not) make.

\subsection{Synonymy Theories and the Constraints}

Arguably, there are three main types of synonymy theory of complex demonstratives: the mechanism theory, the locational theory, and the Gödelian theory. In what follows, I will argue that in light of the constraints above the Gödelian theory is the best of the three. Since these three are arguably the better ones, the Gödelian theory is arguably the best one simpliciter.

\subsubsection{The Mechanism Theory}

According to the mechanism theory, a complex demonstrative 'that F' (or 'this $F$ ') is synonymous with a definite description whose nominal contains ' $F$ ' and a restriction on ' $F$ ' describing a mechanism of reference determination, a complex of physical relations between speaker and referent necessary for the determination of the latter. Let us call these definite descriptions 'mechanism descriptions' (cf. DEVITT, 2004, p. 300; NEALE, 2008b, p. 314).

Hans Reichenbach (1947, p. 284-5) proposed a species of mechanism theory, according to which 'this F' (or 'that F') is synonymous with 'the F pointed to by a gesture accompanying $t$ ', where ' $t$ ' refers to the original complex demonstrative token. Versions of the mechanism theory include: 'this $\mathrm{F}^{\prime}$ (or 'that $\mathrm{F}^{\prime}$ ) is synonymous with 'the F I am perceiving now' (cf. SCHIFFER, 1981); 'this F' (or 'that F') is synonymous with 'the actual F I am demonstrating' (cf. NEALE, 1993); 'this F' (or 'that $\mathrm{F}^{\prime}$ ) is synonymous with 'the $\mathrm{F}$ causing my demonstrative utterance' (cf. LEWIS, 1984); 'this F' (or 'that F') is synonymous with 'the actual F I intend to refer to now'.

For the purposes of the present discussion, I will assume that only one type of mechanism description is synonymous with a complex demonstrative. The main reason for this is that mechanism descriptions are best viewed as representing the right sort of mechanism that helps determine the reference of a complex demonstrative token. On the plausible assumption that there will be 
only one sort of mechanism that is right, one implementation of the theory will be superior. I adopt a model for discussion: 'that F' (or 'this F') is synonymous with 'the actual F I perceive now', where 'I' rigidly refers to the speaker and 'now' rigidly refers to the time of the utterance. ${ }^{13}$

An immediate challenge to the present theory, however, is associated with constraint 6 , according to which a synonymy theory should not predict implausible entailments. Consider 'that book has exactly 100 pages' uttered by me in a particular context (to refer to a particular book in my perceptual field). According to the present theory, this utterance is synonymous with 'the actual book I perceive now has exactly 100 pages' (uttered by me in the same context). Yet, it is counterintuitive that from what I literally express it semantically follows that I exist (LEPORE; LUDWIG, 2000, p. 210). ${ }^{14}$

Moreover, and confirming this point, it is perfectly conceivable that the literal content of my original utterance is the object of a propositional attitude by someone else in a counterfactual world independently of any attitudes whatsoever this person may come to have with respect to me, the actual world or perception (NEALE, 2008b, p. 315; cf. SOAMES, 2002, p. 43-50). The mechanism theory would seem to predict otherwise, against constraint 7.

A further problem relates to constraint 8 , which says that a synonymy theory should not predict implausible associations. By 'association' here I mean a three-place relation relating a speaker and two linguistic tokens such that a speaker associates 'that f' with 'the y' only if he or she forms a belief whose content is <that $\mathrm{f}$ is the $\mathrm{y}>$ (cf. DEVITT, 1981)..$^{15}$ I call this sort of belief an ' $\mathrm{i}$ belief' - short for 'identification-belief'. So, at the root of the present problem is the idea that whenever a speaker utters 'that F' to refer to an F in mind, he or she forms an i-belief whose content is $<$ that $\mathrm{F}$ is the actual $\mathrm{F}$ I perceive now $>$.

I think such associations are at best dubious. For one thing, it is unclear whether young children can always make them. The literature on first language acquisition reports that young children start producing complex demonstratives at around 2 to 3 years of age and many of these utterances are plausibly construed as utterances to refer to a perceptually available object (v. e.g. CLARK, 2001). It would seem remarkable that, say, four-year-olds who are competent with complex demonstratives even possess the concept of actual world ('I and all my surroundings', 'a maximally complete property of the universe') expressed by a rigidifier like 'actual' involved in the i-belief speakers should have when they 
utter a demonstrative token (on the present theory). ${ }^{16}$ Also, the concept of perception is potentially problematic, for depending on the child's age he or she may very well lack any grasp of what perception is, and yet remain competent with demonstratives all the same.

In addition, these associations are dubious for an ulterior reason: the relation between speaker and referent necessary for the determination of the latter will have to be a lot more sophisticated than what is suggested by mere '... perceived by ...' (DEVITT; STERELNY, 1999, p. 61-2). This is so because the mechanism theory must do duty to the idea that complex demonstratives typically pick out the right $\mathrm{F}$ when the speaker perceives (or demonstrates or is caused by) several Fs in the context of the utterance, and doing duty to this idea is likely to involve mechanism descriptions that express very sophisticated concepts, concepts of a scientific semantics probably. Yet, we have no good reason to expect that speakers possess such concepts simply in virtue of their competence. Three or fouryear-olds exemplify the point very well. Should we expect them to have these concepts? I doubt it. Such an expectation would seem to imply an implausible paroxysm of the Piagetian idea that children are 'little scientists'! In sum, it seems too optimistic to think all competent speakers would even have the conceptual resources to make the associations the mechanism theory predicts they make-let alone actually make them in uttering complex demonstratives. For these reasons, I believe the mechanism theory is untenable.

\subsubsection{The Locational Theory}

But, perhaps, synonymy theorists will take the following line: a complex demonstrative 'this F' is synonymous with a definite description 'the F here', and a complex demonstrative 'that $\mathrm{F}$ ' is synonymous with a definite description 'the F there', where 'here' and 'there' refer to the location the intended referent occupies in the context of the utterance (cf. QUINE, 1960; BERNSTEIN, 1997). Let us assume provisionally that 'here' rigidly refers to a location close to the speaker and that 'there' rigidly refers to a location far from the speaker. Let us call a description 'the F here' (or 'the F there') a 'locational description'.

This sort of theory has plausibility. For one thing, it is a truism that objects occupy some location or other. For another, the location an object occupies is often used to identify it, for it is relatively costless from a cognitive 
perspective to invoke locations to elucidate an intended referent. For example, as I order a muffin in a crowded coffee shop, the person behind the counter may ask, 'which muffin do you mean?' to which I may reply, 'that one, next to the biscotti basket'. ${ }^{17}$

An initial problem with the locational theory, however, relates to the crosslinguistic fact that demonstratives are not always used to express a relation of distance between speaker and referent - even if we restrict ourselves to perceptual uses. Thus, suppose I come close to a Matisse painting and utter, while looking at it, 'that painting is an amazing achievement'. This seems like a perfectly felicitous use of 'that painting'. In fact, depending on one's views of Matisse's work, my utterance expresses a literal truth. Yet, if the locational theory is right, the utterance may be infelicitous. After all, I may be too close to the painting. Since there is nothing wrong with my utterance, even if I am very close to the painting, there is something wrong with the theory - at least as stated. ${ }^{18}$

But there is a quick and effective patch for this problem: 'this $\mathrm{F}$ ' (or 'that $\mathrm{F}$ ') is synonymous with 'the F ere', where 'ere' rigidly picks out a distanceneutral location. This certainly accounts for the distance-neutral uses of demonstratives, although arguably it is not nearly sufficient to ground the locational theory.

One important reason is that the locational theory will often make wrong truth conditional predictions. Consider the following scenario. There are two copies of Reimer and Bezuidenhout's Descriptions and Beyond in the room my interlocutor and I occupy. One copy is on the only desk in the room. It is missing page 541. The other copy is inside a drawer this desk has and it is not missing page 541 (suppose my interlocutor and I are unaware of the second copy). The drawer is closed, so the copy it contains is invisible. Suppose, furthermore, that by chance the position of the invisible copy is perfectly symmetrical to the position of the visible one; the invisible copy is exactly under the visible one, the two separated only by the top of the desk. Now, consider my utterance of 'this copy of Descriptions and Beyond is missing page 541' as I look at the visible copy and (presumably) intend to refer to it. Intuitively, this utterance is true because that particular copy is missing page 541 . Yet, the locational theory would seem to predict otherwise. For, according to it the literal content of my utterance is <the copy of Descriptions and Beyond ere is missing page 541>. On the assumption that $<$ the $>$ is Russellian, my utterance would seem to be literally 
false. There are two copies of the book in the relevant location. This is a significant drawback to the locational theory. ${ }^{19}$

Note that resort to a non-descriptive mechanism of reference determination for 'ere' does not seem to help. First, 'ere' seems vaguer in content than 'this' and 'that', from which it follows that scenarios like the one above are not very hard to come across. Second, and worse, whichever non-descriptive mechanism we may invoke to explain the reference of 'ere' is itself sufficient to determine the reference of 'that' and 'this' taken on their own. This undercuts the motivation for an analysis of 'that $\mathrm{F}$ ' as 'the $\mathrm{F}$ ere' in the first place.

Moreover, the locational theory predicts implausible necessities and implausible a priori knowledge (constraints 4 and 5). On the face of it, an utterance of, say, 'that desk is here' does not seem to have a reading on which it is necessary. And neither does it seem to be knowable a priori. But according to (an unrigidified version of) the locational theory it would; its literal content would be <the desk ere is here>, where <ere > and <here > are the same location.

If we add a rigidifier to the locational description, we may avoid the implausible necessity problem, but we face other ones. First, there is the problem of implausible attitude ascriptions (constraint 7). It is perfectly conceivable that a person in a counterfactual world believes the literal content of my utterance of, say, 'that desk is here' without harboring any attitudes whatsoever with respect to the actual world.

In addition, there is the problem of the theory's attribution of implausible associations (constraint 8). It is debatable that all speakers who are competent with complex demonstratives associate rigidified locational descriptions when they utter them. The main reason is that they would have to possess the concept of actual world first, and it is unclear whether we should accept this. For these reasons the locational theory does not appear to be very promising. ${ }^{20}$

\subsubsection{The Gödelian Theory}

Perhaps, then, one will propose the following alternative: a complex demonstrative 'that F' (or 'this F') is synonymous with a definite description 'the F identical to that', where 'that' is a rigidly-referring non-descriptive expression referring to the object the speaker has in mind in uttering the complex demonstrative (v. LEPORE; LUDWIG, 2000; NEALE, 2004; cf. KING, 
2001). I will follow Neale and call these definite descriptions 'Gödelian' and the corresponding synonymy theory 'the Gödelian theory'. ${ }^{21,22}$

I think the Gödelian theory fares very well with respect to all of the eight constraints described, and for this reason I think it is the best synonymy theory of the four. In fact, I am convinced that it is the best synonymy theory of complex demonstratives simpliciter.

First, the Gödelian theory does not predict implausible ambiguities. For, complex demonstratives will be ambiguous insofar as their nominals are ambiguous (constraint 2).

Second, the Gödelian theory does not predict implausible content indeterminacy. For, complex demonstratives will have indeterminate content insofar as their nominals induce content indeterminacy (constraint 3).

Third, the Gödelian theory does not predict implausible necessities (constraint 4). For, 'that $\mathrm{F}$ is identical to that' - assuming both occurrences of 'that' are co-referential - has a reading on which it is necessary (cf. 'that $\mathrm{F}$ is identical to itself').

Fourth, the Gödelian theory does not predict implausible a priori knowledge (constraint 5). For, the content of 'if that $F$ exists, then that $F$ is identical to that' is as good a candidate for a priori knowledge as there is (cf. 'if that $\mathrm{F}$ exists, that $\mathrm{F}$ is identical to itself').

Fifth, the Gödelian theory does not predict implausible entailments (constraint 6). It does predict, though, that from the literal content of an utterance of, say, 'that $\mathrm{F}$ is here', we can infer 'the F identical to that is here', but this does not seem to be a problem.

Sixth, the Gödelian theory does not encourage implausible attitude ascriptions (constraint 7). For, it is very plausible that if someone in a counterfactual world has an attitude with respect to the literal content of 'that F is G' as uttered by me in the actual world this person thereby has the same sort of attitude with respect to 'the F identical to that is G' uttered by me in the original context. ${ }^{23}$

Seventh and last, the Gödelian theory does not seem to attribute implausible associations to speakers. It does entail that in uttering 'that F' a competent speaker thereby forms an i-belief whose content is $<$ that $F$ is the $F$ identical to that $>$. But this, for all we know, is a belief any competent speaker forms in uttering 'that F'. 
Not everyone would agree with this last remark, however. Emma Borg (2003, p. 550) and Stephen Schiffer (2005, p. 1176), for example, have independently suggested that it is dubious that competent speakers associate Gödelian descriptions when they utter complex demonstratives. One way to express their concern is by claiming that it is dubious whether speakers form ibeliefs whose contents are $<$ that $\mathrm{F}$ is the $\mathrm{F}$ identical to that $>$ when speakers utter complex demonstratives to refer to objects they have in mind. For ease of exposition, let us call these i-beliefs 'Gödelian i-beliefs'. Since the issue Borg and Schiffer raise is important, and has not received much attention in the recent literature, a digression is called for.

Arguably, there are two main paths to criticizing the Gödelian theory on the grounds of implausible associations. One path - call it the concept possession path-comprises the idea that (a subclass of) competent speakers become competent with complex demonstratives before acquiring the concepts composing a Gödelian i-belief. A candidate class is very young children and a potentially problematic concept here is token identity, expressed by identical to' in a Gödelian description.

The other path - call it the concept application path - comprises the idea that even though all speakers who are competent with complex demonstratives possess the concepts composing a Gödelian i-belief they do not employ them all when they utter demonstratives. A salient candidate for lack of employment is once again the concept of token identity, and a salient class of speakers is very young children.

As things stand, I believe both argumentative paths fail to show the desired conclusion. Looking at the concept possession path first, it does carry initial plausibility, however. For, one does wonder whether very young children who are competent with complex demonstratives (e.g. 2 or 3-year-olds) possess the concept of token identity. ${ }^{24}$

Interestingly, however, the work of developmental psychologists Elizabeth Spelke, Susan Carey, and Fei Xu among others (v. e.g. XU, 1997) indicates that this type of concern is probably exaggerated. In a series of illuminating experiments, they provide strong evidence that infants as young as four months old already can tell whether an object is the same as the one they perceived before. And from there it is a very small step to the conclusion that these infants have a grasp of token identity. Thus, when the infants reach their second and third 
birthdays and start uttering complex demonstratives to refer to an object in mind, the concept of token identity is an old staple. The Gödelian theorist may point to this evidence and claim that association with a Gödelian description does not exclude young children from the class of speakers who are competent with complex demonstratives.

Turning to the second path - the concept application path - the critic's goal is to show that even though all competent speakers possess all concepts expressed by a Gödelian description, these speakers often fail to employ them all when they utter complex demonstratives. If this were indeed shown, the Gödelian theorist would have some explaining to do. But the problem is that it has not been shown, pace Borg and Schiffer. And the core reason for this, it seems to me, is that once we overcome our doubts with respect to concept possession, there does not seem to be a reliable test left for determining that a speaker does not form a Gödelian i-belief when he or she utters a complex demonstrative.

One proposed test involves asking the speaker what he or she means in uttering a complex demonstrative (cf. SCHIFFER, 2005, p. 1176). But problems arise almost immediately when we attempt to use this test. First, there is the question of what to ask. Should the question be, 'what do you mean to express by your utterance of 'that F'? Or should it be 'by uttering 'that F' do you mean to express 'the F identical to that'? Or should it be something else instead? Those who use this test will be asked for a principled basis. And a lack of basis is potentially harmful because different types of questions may induce different types of answers. It is plausible, for example, that if my subject is adult and understands English and I ask, 'by uttering 'that F' do you mean to express 'the F identical to that'?' pointing to the relevant thing, I will gather more positive evidence (in favor of the Gödelian theory) than if I ask merely, 'what exactly do you mean to express by 'that F'?' The subject may be at a loss by the latter question, or simply point to the intended referent, looking puzzled.

Moreover, speakers may be competent with complex demonstratives but unable to articulate with precision what they mean in uttering them. Young children provide examples. Would the questions above elicit relevant evidence from, say, four-year olds? I doubt it, since they may not have the linguistic means to articulate with precision what they mean (e.g. they might not have expressions for identity relations in their vocabularies). Once we couple this problem with the problem of the principled basis for formulating the questions in the first place, asking the speaker what he or she means appears problematic. Since there 
does not seem to be an alternative test at our disposal, the Gödelian theory seems to stand with respect to the threat of implausible associations.

In this way, we arrive at an appealing hypothesis for why the Gödelian theory also meets the only remaining constraint on synonymy theories, namely the principled basis constraint: meeting constraints 2-8 is the principled basis for the choice of associated description. This dovetails very nicely with Neale's suggestion that Gödelian descriptions provide a 'fool-proof' way of 'regularly interpreting utterances' of complex demonstratives (2004, p. 171).

To conclude: the Gödelian theory comes out as the best synonymy theory of the three. Since these three are arguably the better ones, the Gödelian theory comes out as the best synonymy theory simpliciter. In this way, it provides an empirically and intuitively sound account of how the nominal of a complex demonstrative contributes to its literal content: it is part of a Gödelian description that is synonymous with it.

\section{A Syntactic Interlude: Descriptions in Disguise?}

Yet, if complex demonstratives are Gödelian descriptions semantically, and we assume that linguistic form constrains linguistic interpretation, it is natural to wonder about the syntax of complex demonstratives. For, depending on what we may discover about their syntax, we may have reason to reconsider their semantics. So, what syntax do complex demonstratives have?

To start things off, I should say something about the syntactic framework in which I will locate my discussion. It is the generative framework, and the particular embodiment I will use is the Principles and Parameters model of syntax, the classic P\&P model (v. e.g. CHOMSKY, 1981, 1982, 1986). Within this model, I will ask definite questions about the syntax of complex demonstratives and attempt to assess the Gödelian theory from the vantage point of syntax.

Briefly, my argument in this section will consist in this. Assuming the Gödelian theory in semantics, I will put forth two heuristic assumptions about the syntax of complex demonstratives, 'the naïve assumption about SS' and 'the Gödelian assumption about LF'. I will suggest that holding them both generates serious problems in syntax. I will then propose two strategies of revision, and urge that if we aspire to a unified syntax for bare and complex demonstratives both strategies of revision imply syntactic claims that turn out to be empirically 
disputable. The upshot of my discussion will be that syntax does not compel the acceptance of the Gödelian theory in semantics. I will thus recommend that we cultivate a positive disposition towards complex demonstratives being what they seem to be at face value: non-quantificational terms that refer and describe.

The questions I am going to ask aim at elucidating how a complex demonstrative sentence with the perceptible features it has can receive the interpretation the Gödelian theory assigns it. In P\&P syntax, answering this question involves answering at least two other, more specific questions: 'what is the SS of a complex demonstrative sentence?' and 'what is the LF of this sentence?'These questions will guide my discussion in what follows. ${ }^{25}$

From a very high level of abstraction, let us assume heuristically, as a first pass, that the SS of a sentence like 'that woman sings well' contains the following elements arranged in the following way:

(SS0) $\left[_{\mathrm{IP}}\left[\mathrm{DP}_{\mathrm{DP}}\right.\right.$ that woman] $\left[_{\mathrm{VP}}\right.$ sings well $]$

where 'IP' stands for inflectional phrase, 'VP' for verb phrase, and 'DP' for determiner phrase. ${ }^{26}$ Let us call this heuristic assumption 'the naïve assumption about SS'.

A striking feature of the naive assumption about SS is the lack of a 'null' determiner in the subject DP. ${ }^{27} \mathrm{P} \& \mathrm{P}$ theory teaches us about these entities, often referred to as 'empty categories', syntactically real yet unpronounced and unwritten. They are required for the proper explanation of a number of syntactic phenomena, including the argument structure of certain infinitival clauses, structure preservation of sentences after transformations, argument structure of subjectless clauses in certain languages and more (V. HAEGEMAN, 1994, p. 433-79 for an introductory presentation; cf. CHOMSKY, 1982, p. 17-36). The freedom from null determiners implied by the naïve assumption about SS will serve us well in differentiating strategies on the syntax of complex demonstratives below.

On the hypothesis that the Gödelian theory is true of complex demonstratives, the complex demonstrative 'that woman' is synonymous with a Gödelian description 'the woman identical to that'. Given that LF is the level of syntactic representation interfacing syntax with semantics, it is sensible to ask whether the LF contribution of 'that woman' has the structural organization suggested by the Gödelian description that gives its meaning. On the heuristic assumption that it does, the LF of our sample sentence may have the following (simplified) structure: 
(LF0) $\left[_{\mathrm{IP}}\left[{ }_{\mathrm{DP}}\right.\right.$ the woman $\left[\mathrm{XP}_{\mathrm{P}}\right.$ identical to that $]\left[_{\mathrm{VP}}\right.$ sings well] ]

On the assumption that DPs undergo 'raising' from SS to LF, ${ }^{28}$ the LF we are looking for will actually be somewhat different, but for our immediate purposes we can overlook this. Let us assume, then, that something like LF0 is the LF of 'that woman sings well'. Let us call this heuristic assumption 'the Gödelian assumption about LF'.

We then run into the following (heuristic) question: how do we derive LF0 from SS0 within the P\&P model?

(SS0) $\left[_{\mathrm{IP}}\left[\right.\right.$ DP that woman] $\left[_{\mathrm{VP}}\right.$ sings well] ]

(LF0) $\left[_{\mathrm{IP}}\left[{ }_{\mathrm{DP}} \text { the woman }\left[{ }_{\mathrm{XP}} \text { identical to that }\right]\right]\left[_{\mathrm{VP}} \text { sings well }\right]\right]^{29}$

For the question posed above to have full empirical content, we need to determine XP at LF first. Since determining X involves being clear about several other elements within LF0, I will leave this aside and attempt to proceed on the present level of abstraction. Still, for the question to have empirical content at all, we should make it clear that the demonstrative 'that' leaves a 'trace' after it moves. Traces are essentially copies of moved elements, and they ensure that syntactic structure is preserved after transformations occur. Thus, the presumed derivation we should be assessing relates $\mathrm{SS} 0$ to $\mathrm{LF}^{*}$, rather than $\mathrm{SS} 0$ to LF0, where ' $\mathrm{t}$ ' represents the trace left by the moved 'that':

(SS0) ${ }_{\mathrm{IP}}\left[{ }_{\mathrm{DP}}\right.$ that woman $]\left[_{\mathrm{VP}}\right.$ sings well $\left.]\right]$

(LF0*) ${ }_{\mathrm{IP}}\left[{ }_{\mathrm{DP}}\right.$ the $\mathrm{t}$ woman $\left[{ }_{\mathrm{XP}}\right.$ identical to that $\left.]\right]\left[_{\mathrm{VP}}\right.$ sings well $\left.]\right]$

Given the salient discrepancy between SSO and LF0*, three questions arise:

(Q1) Where does the extra definite article at LF come from?

(Q2) Where does the extra XP at LF come from?

(Q3) Where does the identity relation within the XP at LF come from?

Let us refer to these questions collectively as 'the discrepancy questions' and to the sort of problem they convey 'the discrepancy problem'. 
The discrepancy problem is not the only problem with an attempted derivation from SS0 to LFO*. The demonstrative 'that' would have to move down from SS to LF. Downward movement is generally disallowed in the P\&P model, the main reason for this being that the trace left by a moved element should be 'c-commanded' by it, a requirement downward movement disrespects. ${ }^{30}$ (Intuitively, the c-command requirement preserves the idea that a trace should be within the scope of its antecedent). Let us call this problem 'the downward movement problem'.

So, the situation we seem to be facing is this: on the naïve assumption about SS and on the Gödelian assumption about LF, two problems arise, the discrepancy problem and the downward movement problem. The downward movement problem blocks a derivation from SS0 to LF0*. The discrepancy problem also calls for a solution, and there seems to be no easy way out. Thus, some sort of revision is called for. The obvious candidates for revision are the naïve assumption about SS and the Gödelian assumption about LF. Accordingly, two strategies of revision come into focus.

On the first strategy, we give up the Gödelian assumption about LF but hold fast to the naïve assumption about SS. We thus hypothesize that the LF of a complex demonstrative sentence is syntactically similar to our naïve understanding of its SS. In brief, we simplify LF. On the second strategy, we give up the naïve assumption about SS and hold fast to the Gödelian assumption about LF. We thus hypothesize that the $S S$ of a complex demonstrative sentence is syntactically similar to our Gödelian understanding of its LF. In brief, we embellish SS.

I will call the first strategy 'the simplicity strategy' and the second 'the universalist strategy' (for reasons to become clear below). Each encompasses an independent perspective on the syntax of complex demonstratives, consistent with the Gödelian theory in semantics. I will discuss them separately.

Yet, before proceeding, a word of caution is called for. The syntactic claims to be presented, associated with these two strategies of revision, are motivated and justified on independent syntactic grounds - as attested by the literature on generative syntax in the past decades. Intuitions about linguistic form in the guise of the naïve assumption about SS and the Gödelian assumption about LF play a heuristic role only in the argument of this section, the epistemic heavy lifting being done by independent syntactic argumentation and evidence. 


\subsection{The Simplicity Strategy}

On a naïve understanding of the SSs of sentences containing complex demonstratives, DPs hosting complex demonstratives contain no null determiners. Thus, a natural specification of the SS contribution of complex demonstratives sees the demonstrative morpheme as the determiner, the head of the DP, the D of the DP. Indeed, this sort of view has been fairly standard in the syntax literature (v. e.g. HAEGEMAN; GUERON, 1999, p. 59; ALEXIADOU et al., 2007, p. 93; cf. POSTAL, 1966).

On the simplicity strategy, then, the simplified SS of a sentence like 'that woman sings well' would be something along the following lines:

(SS1) $\left[_{I P 1}\left[{ }_{D P}[\right.\right.$ that $]\left[_{\mathrm{NP}}\right.$ woman $\left.]\right]\left[_{\mathrm{VP}}\right.$ sings well $\left.]\right]$

Since one of our aims is to discover an LF that is syntactically compatible with this SS, a natural candidate would have the following form, where the DP is raised, leaving a co-indexed trace ( $\left.{ }^{\mathrm{t}} \mathrm{t}_{1}\right)$ in its original position:

(LF1) $\left[_{I P 2}\left[{ }_{D P}[\text { that }]\left[_{\mathrm{NP}} \text { woman }\right]\right]_{1}\left[{ }_{\mathrm{IP} 1} \mathrm{t}_{1}\left[\mathrm{VP}_{\mathrm{VP}}\right.\right.\right.$ sings well $\left.\left.]\right]\right]$

From a very high level of abstraction, LF1 differs from SS1 only in having the DP raised. Since this operation is motivated on independent syntactic grounds, the derivation is overall unproblematic.

Yet, one may ask now what this syntactic result has to do with a Gödelian semantics for complex demonstratives. For, by eliminating the Gödelian assumption about LF, which finds Gödelian structure in the syntax, have not we strayed too far from the spirit of the Gödelian theory?

The answer, I think, is 'no'. For, on the present syntactic perspective, demonstrative pronouns like 'that' and 'this' turn out to be determiners, the sort of item from which the DP is projected. ${ }^{31}$ Now, articles are determiners par excellence. Consequently, it is not wholly implausible to hypothesize that for all syntactic ends and purposes demonstrative 'pronouns' are really a species of article (v. POSTAL, 1966). This hypothesis would help to explain, for example, the alleged fact that complex demonstratives cluster with definite descriptions on a number of syntactic phenomena, including 'Weak Crossover Effects', 'Antecedent Contained Deletion', and 'Bach-Peters Sentences' (v. KING, 2001; although for criticism v. ALTSHULER, 2007). And it would also help to explain why definite and indefinite articles in English do not co-occur with demonstratives. If they are 
different realizations of the same syntactic category, we have a straightforward explanation.

Thus, 'that' and 'this' may be seen as Gödelian articles, definite and indefinite articles receiving a Russellian account, Gödelian articles receiving a Gödelian account (v. NEALE, 2004; cf. KING, 2001). This sort of view suggests an improvement to our understanding of how complex demonstrative sentences, with the perceptible features they have, receive the Gödelian interpretation they purportedly receive.

Nonetheless, this picture of complex demonstrative syntax is not without its problems. First, we need to explain how demonstratives, unlike definite and indefinite articles, frequently occur bare in speech and writing, without any nominal complement. This is true of English and of many other languages perhaps all languages. If 'that' and 'this' were a species of article, we should expect them to always occur accompanied.

One way of handling this problem invokes so-called 'intransitive' DP-heads (v. ABNEY, 1987, p. 266), in analogy with intransitive VP-heads (i.e. intransitive verbs). On this view, an important syntactic difference between demonstratives and the standard articles is that the former may be transitive/intransitive whereas the latter are always transitive, always requiring a nominal complement.

Yet, there is something uncomfortable about this proposal even if we stop calling demonstratives 'articles' for a moment. For, we will probably need two lexical entries for demonstratives, one for the transitive form, the other for the intransitive one; such entries would each specify how many and which sorts of complements (if any) a demonstrative expression takes. This suggests that demonstratives are syntactically ambiguous, a prima facie undesirable result. ${ }^{32}$

To avoid this potential problem, one may propose that demonstratives like 'that' and 'this' always occur with a nominal complement (v. NEALE, 2004, p. 118). ${ }^{33}$ It is just that when demonstratives occur bare their complements remain unperceived. In other words, these complements are null.

But problems arise in this line of thought. For one thing, we should specify the content of these allegedly null NP-complements. For, as Neale has pointed out, what would be the point of an expression that is phonetically and semantically empty? (NEALE, 2005, p. 232, n. 116). Perhaps, then, the content of these alleged null NP-complements is something like $<$ thing $>$ or $<$ entity>? If so, 'that', when used demonstratively, would have the semantic import of $<$ that thing $>$ or $<$ that entity $>$. From this it would follow that a 
demonstrative utterance of 'that is a thing', if true, is a logical truth, on a par with 'that thing is a thing', a counterintuitive result.

In response, one may point out that (i) intuitions may differ in these cases and (ii) we need a clearer view of logical truth before we reach any serious conclusion. Since these issues are complicated, one may suggest that the hypothesis stands: bare demonstratives plausibly contain null NP-complements. I accept the point for now, but will come back to it later, near the end of this section.

Still, the idea that demonstratives are a species of article - hence, heads of the DP - has been challenged on independent syntactic grounds. For, it has been shown that despite the unacceptability of phrases containing articledemonstrative combinations in English (and in other languages), their counterparts in several other languages are perfectly acceptable $\left({ }^{*}\right.$ indicates unacceptability):

(a) *This the house

(b) *The house this

(c) *House the this

In Hungarian, Javanese, and Greek, for example, phrases of the form (a) [demonstrative + article + common noun] are perfectly acceptable (v. ALEXIADOU, HAEGEMAN e STAVROU, 2007, p. 110):

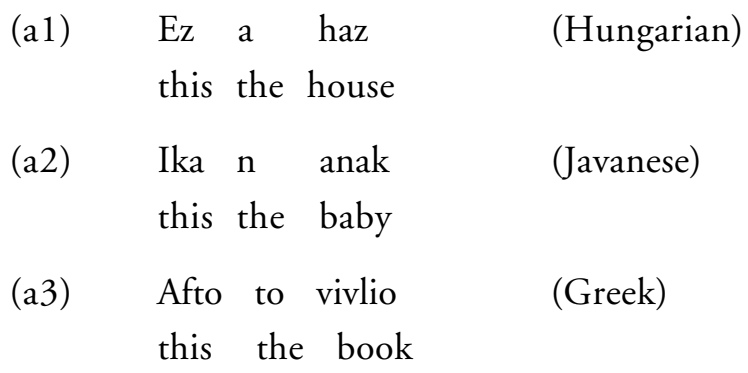

Also, Greek (v. ALEXIADOU et al., 2007; cf. NEALE, 2008a, p. 99), Spanish (see Bruge, 1996), and arguably Ewondo (v. LYONS, 1999, p. 119) accept phrases of the form (b) [article + common noun + demonstrative]: 

(b1)
to vivlio afto
(Greek)
the book this
el libro ese
(Spanish)
the book this

And Romanian accepts phrases of the form (c) [common noun + (affixal) article + demonstrative] (v. GIUSTI, 1997, p. 107-9):

$$
\begin{aligned}
& \text { baiatul acesta (Romanian) } \\
& \text { boy-the this }
\end{aligned}
$$

From the point of view of P\&P syntax, the implications for the structure of the DP in these languages seem clear. Since phrases cannot have two heads, and the canonical position of the definite article is the head of the DP, the demonstrative will have to sit somewhere else in the DP domain.

The question then is what this tells us about English. If we think that the study of the basic structure of the DP is not mostly due to Universal Grammar (UG), that different languages may differ radically with respect to their DPs, the mentioned evidence does not say much about English. Undoubtedly, this is a respectable theoretical stance.

Nonetheless, a growing number of linguists have been arguing for some time now that this is not the right way to think about things. For, according to them, it is methodologically preferable to work with the stronger hypothesis that the DP is essentially the same in its elemental composition and hierarchical organization in all languages (v. CINQUE, 2002, p. 3-4; cf. CHOMSKY, 1982 , p. 16). And if we accept this hypothesis (sometimes referred to as 'the strong universality hypothesis'), the adduced evidence bears significantly on the location of demonstratives in the English DP. By parity of position, it will be hard for one to propose that they occupy the $\mathrm{D}$ position. ${ }^{34}$ This tips us in the direction of the second strategy regarding the relationship between SS and LF of sentences containing complex demonstratives, the universalist strategy.

\subsection{The Universalist Strategy}

On the universalist strategy, one takes very seriously the distribution of articles and demonstratives in the above-mentioned (and other similar) languages. This enterprise practically forces the rejection of the naïve assumption 
about SS. For, by parity of position, if demonstratives are not in $\mathrm{D}$ in these other languages (because there is a definite article in D), they are not in D in English either. Thus, when they occur accompanied by a common noun in English something else will be in D. This something is plausibly a null article. And, indeed, this sort of view has also received independent syntactic support in the syntax literature (v. e.g. BRUGE, 1996; GIUSTI, 1997; cf. HAEGEMAN; GUÉRON, 1999, p. 446-8).

Now, in the universalist strategy, something like the Gödelian assumption about LF is preserved. This requires that a complex demonstrative like 'that woman' be something like 'the woman identical to that' at LF. One promising way of juxtaposing this requirement with the rejection of the naïve assumption about SS is to locate the demonstrative in the left periphery of the DP at SS, a null article occupying $\mathrm{D}$ :

(SS2) $\left[_{\mathrm{IP} 1}\left[{ }_{\mathrm{DP}}\left[{ }_{\mathrm{XP}} \text { that }\right]_{1}\left[\left[_{\mathrm{D}}\right.\right.\right.\right.$ the $]\left[_{\mathrm{NP}}\right.$ woman $\left.] \mathrm{t}_{1}\right]\left[_{\mathrm{VP}}\right.$ sings well $\left.]\right]$

The corresponding Gödelian LF is LF2, with the DP raised, as is usual:

(LF2) $\left[_{\mathrm{IP} 2}\left[_{\mathrm{DP}}\left[{ }_{\mathrm{XP}} \text { that }\right]_{1}\left[\mathrm{D}_{\mathrm{D}} \text { the }\right]\left[_{\mathrm{NP}} \text { woman }\right] \mathrm{t}_{1}\right]_{2}\left[_{\mathrm{IP} 1} \mathrm{t}_{2}\left[{ }_{\mathrm{VP}}\right.\right.\right.$ sings well $\left.]\right]$

Two things call for immediate explanation. First, the 'identical to' locution, which figured previously in LF0, is absent from both SS2 and LF2. One may find this objectionable, but insofar as the locution is motivated primarily by a particular formal implementation of the Gödelian semantics, we do not need to have a problem. Furthermore, the eradication of this locution is attractive in that it obviates the question about its syntactic origin (Q3 above). If this is right, all we need in order to capture the idea that 'that woman' is syntactically 'the woman identical to that' is the combination 'article + demonstrative + common noun' in the same DP domain (viz. 'the woman that'). This is precisely what SS2 and LF2 offer.

Second, at SS2 there is a trace within the DP (viz. ' $t_{1}$ '), bound by the maximal projection XP which hosts 'that'. This means that the linear order we find at SS2 is derived, the demonstrative being inserted lower, moving up to the left periphery of the DP at SS. ${ }^{35}$ This hypothesis has received good empirical support from cross-linguistic evidence (and is consistent with the word order we find in English) (see BRUGE, 1996; ALEXIADOU et al., 2007). In fact, it seems plausible if we aim at an explanation of the different word orders 
involving demonstratives and articles across different languages, for if we postulate a single word order at the base with the demonstrative inserted low, we can then explain the different word orders in terms of upward movement and parametric variation.

Thus, the universalist strategy suggests an improvement to our understanding of how complex demonstrative sentences, with the perceptible features they have, can receive the Gödelian interpretation they purportedly receive.

Nevertheless, the present syntactic perspective is not without its difficulties. The most important one is associated with the idea that 'that' and 'this' will be something like adjuncts, i.e. modifiers (cf. 'the blue book', 'the that book', 'the book of poems', 'the book that'). Thus, they will require an element to modify, in this case a nominal element. But, as noted above, demonstratives occur bare, without any nominal supplementation, in which case they do not seem to modify anything. (Of course, one could always postulate a null NP supplement, but it is very hard to find satisfactory empirical evidence for this. $)^{36}$

Furthermore, inferences of the form 'that F is G' ' 'that is G' are valid. If demonstratives were modifiers, what would they modify in the conclusion of these inferences? One answer might be: a null NP, with the semantic import of $<$ thing $>$. So, the inference type would be 'that the F is G' $\backslash$ 'that the thing is G'. But now we face a problem alluded to above, and a quite serious one in my opinion: there is no syntactic evidence demonstrating the existence of null NPs in bare demonstratives. From a syntactic point of view, bare demonstratives seem to be perfectly autonomous items. Thus, we seem to be facing a significant empirical problem on the universalist strategy.

It should be noted, incidentally, that both the simplicity and the universalist strategies postulate a null NP in the syntax of bare demonstratives, though the syntactic role this NP plays is different in each strategy. On the simplicity strategy, the null NP must be a complement, required by the demonstrative morpheme, which is essentially an article. Thus, bare 'that' is syntactically $\left[_{D P}[\right.$ that $]\left[_{N P}\right.$ thing $\left.]\right]$, on a par with $\left[_{D P}\left[{ }_{D}\right.\right.$ the $\left[_{N P}\right.$ thing $\left.]\right]$. On the universalist strategy, by contrast, the null NP need not be a complement; instead, it may be an adjunct that modifies a null NP, itself a complement to a null article. On this strategy, bare 'that' is syntactically $\left[_{\mathrm{DP}}\left[_{\mathrm{D}}\right.\right.$ the $\left[_{\mathrm{NP}}\right.$ thing] $\left[_{\mathrm{XP}}\right.$ that $\left.]\right]$. However, given the lack of syntactic evidence for null NPs in the syntax of bare demonstratives, it is sensible to wonder whether we are on the right track. Where should we go from here? 
I see three options: (i) endorse the simplicity strategy or the universalist strategy and live with the cost of null NPs in the syntax of bare demonstratives, a cost that can be partially settled theoretically; (ii) embrace a fundamental syntactic ambiguity between bare and complex demonstratives; or (iii) seek syntactic unification while preserving the insight that bare demonstratives are autonomous nominal items. ${ }^{37}$

\subsection{Referring and Describing}

Even though (i) is the more popular view and (ii) also has followers (v. e.g. DECHÁINE; WILTSCHKO, 2002), I think we might very well benefit from the pursuit of (iii), according to which bare demonstratives are autonomous NPs. If they occur accompanied, in 'complex form', they are still NPs but NPs that combine with other NPs to form nominal complexes. Note that there is nothing extraordinary about nominal complexes in natural language; plausible candidates would include 'we philosophers', 'you linguists', 'them kids', 'Princeton University', 'Carnegie Hall' and arguably 'I myself', 'William of Ockham' and 'Saul Aaron Kripke'. We need, of course, to explain the syntax of nominal complexes (no trivial task). Since my purpose here is not to argue for any particular syntactic proposal, I will have no theory to offer. But I do have two suggestions to make, which seem to me to carry initial plausibility. ${ }^{38}$

First, we might consider the hypothesis that complex demonstratives are adjunction structures, essentially NP-NP combinations of the form $\left[_{\mathrm{NP}}\left[_{\mathrm{NP}}\right.\right.$ that $]$ $\left.\left.{ }_{\mathrm{NP}} \mathrm{man}\right]\right]$. This seems to make some sense of the similarities between complex demonstratives, complex pronouns (e.g. 'we philosophers') and descriptive names (e.g. 'Carnegie Hall') - and also of full names like 'Saul Aaron Kripke'.

Second, we might consider the idea that complex demonstratives instantiate a 'relator phrase' (RP) in the sense of Marcel den Dikken (2006). On this perspective, complex demonstratives may have the following structure: $\left[_{\mathrm{RP}}\left[_{\mathrm{NP}}\right.\right.$ that $]\left[_{\mathrm{R}}, \mathrm{r}\left[_{\mathrm{NP}} \mathrm{man}\right]\right]$, where ' $\mathrm{r}$ ' is the head of the relator phrase (and may remain unpronounced). Note that RPs not only have the ability to illuminate the syntax of complex pronouns and descriptive names, but also throw light on the syntax of small clauses, for example: 'I consider this an interesting proposal. The constituent in italics might instantiate an RP: $\left[_{R P}\left[_{N P}\right.\right.$ this $]\left[_{R}, r\left[{ }_{D P}\right.\right.$ an interesting proposal]]. 
Surely, a lot more needs to be said about both suggestions if we are to accept them. Yet, in face of the empirical problem of null NPs in the syntax of bare demonstratives, and motivated by the desire to unify the syntax of bare and complex demonstratives, we may very well make progress pursuing these and kindred alternatives.

In any event, the moral of the present discussion for the main theme of this essay is merely this: P\&P syntax does not force us to see complex demonstratives as Gödelian descriptions. For one, we do not seem to be forced to adopt either the simplicity or the universalist strategies in syntax. For another, even if we adopted either, a Gödelian semantics would not follow from this. Thus, we should cultivate a positive disposition towards complex demonstratives being what they seem to be at face value: non-quantificational terms that refer and describe.

In the next section, I will offer a methodological argument that shows that from a semantic point of view complex demonstratives probably are nonquantificational terms that refer and describe.

\section{The Domino Argument}

I will start this section with what seems to me a rather plausible observation: the literal content of bare demonstratives is probably not given by associated descriptions. This negative claim includes two negative sub-claims: (i) the literal content of a bare demonstrative is not given by an associated description and (ii) the referent of a bare demonstrative is not determined by an associated description.

Why think (i) and (ii)? First, because analyzing bare demonstratives in terms of impoverished locational descriptions (viz. 'the thing $\mathrm{t} /$ here') would produce unsatisfying results, since locational descriptions without a substantive nominal would very often make wrong truth-conditional predictions. A simple utterance like 'this is yours; take it' is analyzed as 'the thing here is yours; take it', which is trivially false, since an enormously large number of 'things' occupy any one location. Second, analyzing bare demonstratives in terms of impoverished Gödelian descriptions (viz. descriptions of the form 'the thing identical to that') would not work either, since this proposal would appear to be ad hoc (NEALE, 1990; cf. NEALE, 2008).

Thus, the better option for a description theory of bare demonstratives would probably be some version of the mechanism theory, which builds a 
mechanism of reference determination into the descriptive content of the bare demonstrative. But then we run into a methodological problem, described by Lepore and Ludwig in the following passage (v. DEVITT, 2004):

The description approach is a form of mimicry, piggybacking on an independent means for securing a referent for predication as a way of imitating the behavior of demonstratives. It attempts to treat "that" as a quantifier by treating the means by which its referent is determined, namely, by demonstration, as a general condition to be met for singling out an object by way of a definite description. But the fact that it must appeal to an independent means for securing an object for predication shows that it is a counterfeit of the hard coin of demonstration. The same work is being done twice over, but less well the second time around. The act of demonstration itself secures the object for predication. It would be pointless to go on to try to secure it a second time by means of the matrix " $\mathrm{x}$ is demonstrated by $s$ at t”. (2000, p. 210-11)

If we understand 'demonstration' as any 'act of referring' - as Lepore and Ludwig do - the passage applies equally well to any mechanism theory as conceived in section 2.1.1. Since mechanism description theories are the only description theories in the running for bare demonstratives, bare demonstratives are not synonymous with descriptions, but very plausibly have their contents determined non-descriptively, probably by the very mechanisms of reference determination mechanism descriptions attempt to describe.

But then the Gödelian theory of complex demonstratives faces a similar fate. For, given a non-descriptive semantics for bare demonstratives and the contribution the nominal ' $F$ ' makes to the literal content of 'that $F$ ', it becomes entirely unclear what distinctive semantic work Gödelian descriptions are supposed to be doing. Modifying Lepore and Ludwig's passage slightly, the point can be made in their own words, mostly (modifications in italics):

The Gödelian description approach is a form of mimicry, piggybacking on an independent means for securing a referent for complex demonstratives as a way of imitating the behavior of complex demonstratives. It attempts to treat "that $F$ " as a quantifier by treating the means by which its referent is determined, namely, by 
the application of $F$ to the referent of "that", as a general condition to be met by way of a definite description. But the fact that it must appeal to an independent means for reference determination shows that it is a counterfeit of the hard coin. The same work is being done twice over, but less well the second time around. The application of $F$ to the referent of "that" itself secures the referent of "that F". It would be pointless to go on to try to secure it a second time by means of the matrix " $x$ is identical to that".

Since Gödelian descriptions are the only ones in the running for complex demonstratives, complex demonstratives are probably not synonymous with descriptions of any kind.

But what are complex demonstratives, if not disguised descriptions? As suggested above, they are what they seem to be at face value: non-quantificational terms that refer and describe: descriptive designators, I dub them. On this view, 'that F' refers to * iff 'that' refers to * and * is $\mathrm{F}$, and the literal content of 'that $\mathrm{F}$ ' is something along the lines of $<^{*}, \mathrm{~F}>$ (v. RICHARD, 1993; DEVER, 2001; cf. BURGE, 1974; DEVITT; STERELNY, 1999; DEVITT, 2004 for analogous alternatives).

Note that the descriptive designator view adapts very well to the source of the constraints on description theories discussed in section 2. For, it does not entail ambiguities or content indeterminacy unless nominals trigger them. Furthermore, it avoids implausible modal, epistemic, and psychological consequences. And, it elucidates, in a theoretically satisfying way, ${ }^{39}$ how the meaning of a complex demonstrative depends on the meanings of its parts. In sum, the descriptive designator view appears to conserve what is right, and dispense with what is wrong, with the Gödelian theory.

\section{Concluding Remarks}

In this essay, I argued for three main points: (i) that the Gödelian theory is the best synonymy theory of complex demonstratives; (ii) that P\&P syntax does not force us to see complex demonstratives as synonymous with Gödelian descriptions; and (iii) that on methodological grounds we should reject the Gödelian theory and adopt the descriptive designator alternative.

At the outset, I framed my discussion in terms of the contribution the nominal makes to the literal content of complex demonstratives, claiming that 
this contribution should not be understood via definite descriptions. One might have thought that this choice of framing was somewhat unorthodox, since arguably the main thrust of description theories of complex demonstratives was never the nominal perse, which is given by the complex demonstrative itself, but rather the something we know not what that helps to pick out the referent from the available candidates satisfying the nominal in the context of the utterance. To some, this amounts to the idea that description theories of complex demonstratives are primarily theories of nominal restriction or nominal completion rather than theories of nominal contribution per se.

In the face of the explanatory dispensability of associated descriptions to the content of bare demonstratives, however, the only plausible explanatory role left for associated descriptions to play with respect to the content of complex demonstratives is that their nominals make a contribution. Hence the Gödelian proposal, with its suspicious recourse to the idlest of all relations, the identity relation. But we do not need associated descriptions to explain that the nominal makes a contribution (pace NEALE, 2008: 308-13). Nominal application is sufficient. ${ }^{40}$ Thus, Gödelian descriptions are dispensable posits, danglers in our overall epistemic picture of demonstrative content.

So, to the question 'are complex demonstratives synonymous with descriptions?' the answer (it seems to me) is 'probably not'. And to the question, 'are there terms in natural language that are both referential and descriptive without being quantificational?' the answer (it seems to me) is 'probably yes'. Complex demonstratives are among them. ${ }^{41}$

\section{Notes}

${ }^{1}$ My thanks to Michael Devitt, Kent Bach, Stephen Neale, Jonathan Adler, Robert Fiengo, Marcel den Dikken and an anonymous referee for Revista de Estudos da Linguagem for helpful comments and suggestions on a previous version.

${ }^{2}$ In this essay, I will not discuss demonstratives in the plural.

${ }^{3}$ I understand literal content as equivalent to semantic content.

${ }^{4}$ In my usage, and following Stephen Neale, 'Gödelian descriptions' are descriptions of 'the sort used in spelling out Gödel's slingshot argument' (NEALE, 2004, p. 171).

${ }^{5}$ One may wonder at this point whether complex demonstratives and definite descriptions, Gödelian descriptions in particular, could be synonymous. For, on the 
assumption that these expressions are different syntactically, they should be different in meaning, one may suggest. In response, I should say three things. First, we need to be clear on what constitutes a syntactic difference between two linguistic strings. Second, we also need to be clear on what constitutes a meaning difference. And, third, it seems very much open to question that syntactic differences entail meaning differences. For, if this were true, syntax would appear to supervene on meaning, in the sense that, necessarily, for any difference at the supervening level (syntax), there would be a difference at the base level (meaning), in which case meaning would appear to fix syntax. Since this result is unacceptable to many, I conclude that there is nothing wrong with the working hypothesis that complex demonstratives and definite descriptions are synonymous. I will reject this synonymy hypothesis later on, but for reasons that are independent of the alleged autonomy of syntax vis-à-vis semantics.

${ }^{6}$ Although the label 'descriptive designator' is new with me, the view itself is not. Actually, there is a family of implementations of the same underlying idea in the philosophical literature. Among the principal ones are those by Mark Richard (1993) and Josh Dever (2001), on the one hand, and Tyler Burge (1974) and Michael Devitt (2004) on the other. At present, I am inclined to join the Richard camp - due to broad agreement with respect to foundational issues in semantics, issues ultimately related to the nature of linguistic meaning and content. However, I will not commit to any particular implementation of the view in this paper.

${ }^{7}$ The other referential uses I have in mind are memory uses (e.g. 'that lady last night was a riot, wasn't she?) and anaphoric uses with referential antecedents (e.g. here, take this; this pill will help you with your cold). In my view - and departing from Gareth Evans (1982) - perceptual, memory, and anaphoric uses are the three basic types of referential use complex demonstratives have. I borrow the label 'memory' from Kent Bach's illuminating discussion of singular thought. See his 1994.

${ }^{8}$ Note that definite descriptions themselves also have this "dual nature", as an anonymous reviewer points out. In my view, it is eminently plausible to postulate a referential/non-referential ambiguity in both complex demonstratives and definite descriptions (see next footnote).

${ }^{9}$ Jeffrey King has forcefully argued that a subclass of non-referential uses - the class of what he calls 'no demonstration no speaker reference' uses (2001, p. 3) - constitutes a serious challenge to a unified referential semantics for complex demonstratives. I agree with King, but propose to face the challenge in the following way: complex demonstratives - the linguistic types - are ambiguous between referential and nonreferential meanings. In my view, the proper sense of lexical ambiguity here is semantic polysemy, the sort of ambiguity that comes about by the fossilization of communicative 
intention into coded content, the ambiguity that commonly carries over across different languages (in sharp contrast to homonymies, which are typically intralinguistic).

${ }^{10}$ Devitt 2004 contains a similar list although its focus is incomplete definite descriptions.

${ }^{11}$ The intended contrast here is with logical or mathematical properties, which are arguably a priori knowable. For example, the property of self-identity is a property every individual whatsoever has. Arguably, this is a logical property.

${ }^{12}$ An anonymous reviewer points out that in order to understand an utterance of 'that river is polluted' relative to a context, an interpreter in a counterfactual situation might very well harbor some sort of attitude with respect to an utterer. As I see it, the point in the passage regards the nature of the semantic content (or literal content) of an utterance of 'that river is polluted' relative to a context (i.e. the proposition semantically expressed relative to the context). This sort of content need not to involve reference to utterers at all. Something more abstract, akin to Kaplanian character, on the other hand, might involve reference to utterers (but, I emphasize, the point here regards semantic or literal content).

${ }^{13}$ The notion of rigidity I use is Kripkean (KRIPKE, 1980): 'a' rigidly refers to * iff 'a' refers to ${ }^{*}$ in all possible worlds where * exists and 'a' does not refer to anything in other worlds. Nathan Salmon (2005) has called this kind of rigidity 'persistence'.

${ }^{14}$ An anonymous reviewer complains about my reliance on intuitions here. As I see it, and following many in the philosophical literature, an intuition about $\mathrm{X}$ is an unreflective judgment or belief a speaker has about X. In this way, it would seem very surprising that the literal (or semantic) content of an utterance of 'that book has exactly 100 pages' relative to a context involves its utterer. On a very clear and intuitive level, the content of the utterance is simply not about an utterer, but about a particular book. I should also point out that, in stating this problem, I am making an assumption (made by Lepore and Ludwig) according to which definite descriptions are Russellian. Strawsonians will, of course, complain, but I do not see how an endorsement of Strawson here would save the mechanism theory as a whole.

${ }^{15}$ Throughout I use the convention of surrounding an expression with angled brackets to refer to its (literal or semantic) content.

${ }^{16}$ By this I mean that these children do not have the concepts required, not just the linguistic means to express them. I believe it is unwarranted to attribute to children at this age the possession of the concept of "actual world" as it is understood by philosophers of language and modal logicians. 
${ }^{17}$ One problem with the locational theory relates to other referential uses of complex demonstratives, like memory and anaphoric. For, what role would a locational element play in these cases? Since arguably there are sufficient and independent grounds to reject the locational theory, overlooking this problem should not be a problem.

${ }^{18}$ There are languages containing demonstratives that are always neutral with respect to speaker/referent distance (v. LYONS, 1999, p. 112). French is an example; 'ce' is itself neutral with respect to distance, although it may occur accompanied by the morphemes 'ci' and 'là', which imply closeness and distance, respectively.

${ }^{19}$ As an anonymous reviewer points out, I am assuming that the (actual) truthconditions of the proposition literally (or semantically) expressed by the original utterance of 'this copy of Descriptions and Beyond is missing page 541' are constituted by the "real world as it is" - as opposed to a "real world as represented by speaker and hearer in the context of the utterance".

${ }^{20}$ One may propose an alternative synonymy theory, which may be called 'the situational theory': 'that F' (or 'this F') is synonymous with 'the F in s', where $s$ is a situation containing the right $\mathrm{F}$. The main problem with this theory is that being a member of a situation (or in a situation, as one may prefer to put it) probably plays no distinctive semantic work when it comes to deictic referential complex demonstratives. For, whichever mechanisms of individuation of situations we invoke would appear to be themselves sufficient to determine the reference of 'that' in 'that F'. Reference to situations would thus be superfluous.

${ }^{21}$ Actually, Neale $(2004 ; 2008 b)$ claims that complex demonstratives are equivalent to indefinite Gödelian descriptions. I will not pursue these differences here.

${ }^{22}$ An alternative name for this sort of theory might be 'the haecceity theory', according to which a complex demonstrative is synonymous with a haecceity description, a definite description that denotes a particular object via its haecceity. As I construe it, a haecceity is the property an object a has of being identical to itself (viz. lx $(\mathrm{x}=\mathrm{a})$ ). Compare Robert Adams's use of 'thisness': "a thisness is the property of being identical with a certain particular individual - not the property that we all share, of being identical with some individual or other, but my property of being identical with me, your property of being identical with you, etc." (1979, p. 6). One reason I stick with 'Gödelian theory' and 'Gödelian description' is that I am not certain that I should graft the Gödelian approach onto the hypothesis that English 'that' is a (pronominal) predicate.

${ }^{23}$ This point may be disputed, since we can conceive of worlds where speakers (competent with demonstratives) simply lack the concept of token identity. There is the question, of course, of how far these worlds are from us, and hence how relevant to our practices they are. I will not pursue this here. 
${ }^{24}$ Another potentially problematic concept here is the concept expressed by 'the'. If it is Russellian, competence with demonstratives may very well involve a grasp of the concept of totality.

${ }^{25}$ One may suggest that this discussion should be couched in Minimalist terms, as opposed to the classic GB P\&P terminology, which is arguably 'outdated'. I favor classic P\&P because talk of optimal design of the language faculty seems very much open to question and classic P\&P seems largely adequate empirically.

${ }^{26}$ I assume the DP-hypothesis without discussion (v. e.g. ABNEY, 1987), although close to the end of this section it will become clear that this assumption is unnecessary. ${ }^{27}$ This particular SS representation is highly idealized. In P\&P syntax, SS is a level of representation where all sorts of null elements reside. For example, under the socalled 'VP-internal subject hypothesis', subjects are born VP-internally at DS, moving up to Spec, IP at SS, leaving a co-indexed trace in their original VP positions. I bypass such considerations to achieve a simpler exposition. For much the same reasons, I bypass talk of an agreement layer between DP and NP. None of this should detract from the main points I intend to make.

${ }^{28} \mathrm{On}$ the assumption made by Gödelian theorists that 'the F' is a type of natural language quantifier, the kind of raising alluded to here is $\mathrm{QR}$, quantifier raising, which maps SS to LF representations by 'Chomsky-adjunction' (cf. MAY, 1985; NEALE, 1994).

${ }^{29}$ Even though this way of putting things may seem odd to syntacticians, it should be emphasized that the derivations are not supposed to be completely realistic. They are mainly heuristic.

${ }^{30}$ A node $\mathrm{X}$ c-commands a node $\mathrm{Y}$ iff the first branching node dominating $\mathrm{X}$ dominates Y (and neither dominates the other). See e.g. HAEGEMAN, 1994, p. 134.

${ }^{31}$ There appears to be an equivocation in the use of 'determiner' in the philosophical literature. Some use it to refer to an item that 'combines with nominals to form complex noun phrases' (v. e.g. LEPORE; LUDWIG, 2000, p. 203) while others use it to refer to a certain position in the DP, the head position of the DP. In this essay, I always use the term in this second sense.

${ }^{32}$ Furthermore, there would be little point in calling such intransitive determiners 'determiners' since nothing syntactic would appear to compel us to see them as determiners. Why not call them 'NPs' instead?

${ }^{33}$ Definite articles $d o$ at times occur without complements, but the explanation for this phenomenon is presumably 'syntactic deletion'. Portuguese exemplifies this: 'o carro do João é mais rápido do que $\boldsymbol{o}[\ldots]$ da Maria', where the bold italicized 'o' is the (masculine 
singular) definite article without a complement - the brackets indicate where the complement would go. In English, this example would be (literally) 'the car of John is faster than the [...] of Maria' which would be better expressed by 'John's car is faster than Maria's [...]', where the nominal 'car' is deleted from the constituent 'Maria's'. These cases of deletion, however, seem independent of whether or not bare demonstratives always have null NP-complements. Cf. LASNIK; SAITO, 1992, p. 161.

${ }^{34}$ Which is not to say, of course, that we are rationally forced to leave the simplicity strategy. Nevertheless, we do not seem compelled to accept it either, which opens the way for alternative (and perhaps more plausible) analyses.

${ }^{35}$ It should be pointed out that the common noun itself arguably occupies a derived position at SS, being inserted lower and then moving up closer to the article. I will leave this complication aside (v. BRUGE, 1996 for further discussion).

${ }^{36}$ Actually, things are more complicated than this suggests. There are at least five different ways in which we can understand demonstratives within the universalist strategy: demonstratives are (a) adjuncts, maximal projections that are sisters to N', dominated by NP, itself sister to D; (b) demonstratives are adjective heads, immediately dominated by AP, itself sister to D; (c) demonstratives are specifiers of a dedicated functional phrase between DP and NP; (d) demonstratives are elements of a relative clause (CP) adjoined to DP (cf. the blue car; the car which is blue; the that car; the car which is that); (e) the demonstrative 'that' is always a complementizer. All of these options have one thing in common, however, which is crucial to the present discussion: they require null NP supplements when demonstratives occur bare. This justifies the simplification in the body of the text.

${ }^{37}$ There are at least three ways in which we can understand the syntactic autonomy of bare demonstratives: (i) they require no complements (unlike articles); (ii) they require nothing to modify (unlike adjuncts/adjectives); (iii) they are DP-external. Irish is arguably a language in which demonstratives are DP-external (v. LYONS, 1999, p. 120).

${ }^{38}$ This sort of proposal is consistent with the DP-hypothesis though it does not require it.

${ }^{39}$ An anonymous reviewer points out that, on the descriptive designator view, distality differences between 'this' and 'that' remain unaccounted for. This need not be so, since there are at least two approaches available to the descriptive designator theorist: (i) deny that there is any true semantic difference, locating in pragmatics the presumed difference; (ii) explain the differences on a more abstract semantic level, something akin to Kaplanian character (in contrast to semantic or literal content).

${ }^{40}$ Nominal application is meant to be a relationship between a predicate (or predicative expression) and an object or entity. A predicate applies to an object iff 
the object exemplifies the property described by the predicate. In this way, 'that F' refers to ${ }^{*}$ iff 'that' refers to ${ }^{*}$ and ' $\mathrm{F}$ ' applies to ${ }^{*}$ - in other words, iff * is the referent of 'that' and is $\mathrm{F}$.

${ }^{41}$ Examples include descriptive names (e.g. 'Carnegie Hall'), complex pronouns (e.g. 'you oboists'), and (semantically) referential descriptions (e.g. 'the concert last night'). After all, why should describing with a term always imply quantifying?

\section{References}

ABNEY, Steven. The English Noun Phrase in Its Sentential Aspects. Cambridge (MA), 1987. Tese (Doutorado) - Departamento de Linguística e Filosofia, MIT.

ALEXIADOU, Artemis; HAEGEMAN, Liliane; STAVROU, Melita. The Noun Phrase in the Generative Tradition. Berlin: Mouton, 2007.

ALTSHULER, Daniel. WCO, ACD, and what they reveal about complex demonstratives. Natural Language Semantics, v. 15, p. 265-77, 2007.

BACH, Kent. Thought and Reference. 2. ed. Oxford: The Clarendon Press, 1994.

BERNSTEIN, Judy. Demonstratives and Reinforcers in Romance and Germanic languages. Lingua, v. 102, p. 87-113, 1997.

BORG, Emma. Review of 'Complex Demonstratives'. Mind and Language, v. 18, p. 546-551.

BRAUN, David. Structured characters and complex demonstratives. Philosophical Studies, v. 74, p. 193-219, 2004.

BRUGE, Laura. Demonstrative movement in Spanish: a comparative approach. University of Venice Working Papers, v. 6, n.1, p. 1-53, 1996.

BURGE, Tyler. Demonstrative constructions, reference, and truth. Journal of Philosophy, v. 71, p. 205-223, 1974.

CHOMSKY, Noam. Lectures on Government and Binding. Foris: Dodrecht, 1981.

CHOMSKY, Noam. Some Concepts and Consequences of the Theory of Government and Binding. Cambridge, MA.: MIT Press, 1982.

CHOMSKY, Noam. Barriers. Cambridge, MA.: MIT Press, 1986.

CINQUE, Guglielmo. Mapping functional structure. In: CINQUE, G. (Org.). Functional Structure in the DP and the IP: The Cartography of Syntactic Structures, v.1. Nova Iorque: Oxford University Press, 2002. p. 3-14. 
CLARK, Eve. First Language Acquisition. Cambridge: Cambridge University Press, 2001. DÉCHAINE, R.; WILTSCHKO, M. Decomposing Pronouns. Linguistic Inquiry, v. 33, p. 409-442, 2002.

DEVER, Josh. Complex demonstratives. Linguistics and Philosophy, v. 24, p. 271-330, 2001.

DEVITT, Michael. The case for referential descriptions. In: REIMER, M.; BEZUIDENHOUT, A. (Org.). Definite Descriptions and Beyond. Oxford: Clarendon Press, 2004. p. 280-305.

DEVITT, Michael; STERELNY, Kim. Language and Reality. 2. ed. Cambridge, MA.: MIT Press, 1999.

DIKKEN, Marcel den. Relators and Linkers. Cambridge, MA.: MIT Press, 2006. GIUSTI, Giuliana. The categorial status of determiners. In: HAEGEMAN, L. (Org.). The New Comparative Syntax. Londres: Longman, 1997. p. 95-123

HAEGEMAN, Liliane. Introduction to Government and Binding Theory. 2. ed. Malden: Blackwell, 1994.

KAPLAN, David. Demonstratives. In: ALOMG, J.; PERRY, J.; WETTSTEIN, H. (Org.). Themes from Kaplan. Oxford: Oxford University Press, 1989. p. 481-563.

KING, Jeffrey. Complex Demonstratives. Cambridge, MA.: MIT Press, 2001.

KRIPKE, Saul. Naming and Necessity. Cambridge, MA.: Harvard University Press, 1980.

LASNIK, Howard and SAITO, Mamoru. Move-a. Cambridge, MA: MIT Press, 1992. LEPORE, Ernest; LUDWIG, Kirk. The semantics and pragmatics of complex demonstratives. Mind, v. 109, p. 199-240, 2000.

LEWIS, David. Putnam's paradox. Australasian Journal of Philosophy, v. 62, p. 221-236, 1984.

LYONS, Christopher. Definiteness. Cambridge: Cambridge University Press, 1999.

NEALE, Stephen. Descriptions. Cambridge, MA.: MIT Press, 1990.

NEALE, Stephen. Term limits. Philosophical Perspectives, v. 7, p. 89-123, 1993.

NEALE, Stephen. This, that and the other. In: REIMER, M.; BEZUIDENHOUT, A. (Org.). Definite Descriptions and Beyond. Oxford: Clarendon Press, 2004. p. 68-182.

NEALE, Stephen. Pragmatism and Binding. In: SZABÓ, Z. (Org.). Semantics versus Pragmatics. Oxford: Clarendon Press, 2005. p. 165-285.

NEALE, Stephen. Heavy hands, magic and scene reading traps. European Journal of Analytic Philosophy, v. 3, p. 77-132, 2008 a. 
NEALE, Stephen. Term limits revisited. Philosophical Perspectives, v. 22, p. 271-337, 2008b.

MAY, Robert. Logical Form. Cambridge, MA.: MIT Press, 1985.

PERRY, John. Frege on demonstratives. Philosophical Review, v. 86, p. 474-497, 1977.

POSTAL, Paul. On so-called 'pronouns' in English. In: REIBEL, D.; SCHANE, S. (Org.). Modern Studies in English. Englewood Cliffs, NJ: Prentice Hall, 1966. p. 201-224.

QUINE, W.V.O. Word and Object. Cambridge, MA.: MIT Press, 1960.

REICHENBACH, Hans. Elements of Symbolic Logic. Londres: McMillan, 1947.

RICHARD, Mark. Articulated terms. Philosophical Perspectives, v. 7, p. 207-230, 1993.

SALMON, Nathan. Demonstrating and necessity. Philosophical Review, v. 111, p. 497-537, 2002.

SALMON, Nathan. That F. Philosophical Studies, v. 141, p. 263-280, 2008.

SCHIFFER, Stephen. Indexicals and the theory of reference. Synthese, v. 49, p. 430-100, 1981.

SCHIFFER, Stephen. Descriptions, indexicals, and belief reports. Mind, v. 104, p. 107-131, 2005.

SCHIFFER, Stephen. Russell's theory of definite descriptions. Mind, v. 114, p. 113583, 2005.

SOAMES, Scott. Beyond Rigidity. Oxford: Oxford University Press, 2002.

STANLEY, Jason; SZABÓ, Zoltán. On quantifier domain restriction. Mind and Language, v. 15, p. 219-261, 2000.

WETTSTEIN, Howard. Demonstrative reference and definite descriptions. Philosophical Studies, v. 40, p. 241-57, 1981.

WILSON, George. Reference and pronominal descriptions. Journal of Philosophy, v. 88, p. 359-87, 1991.

$\mathrm{XU}$, Fey. From Lot's wife to a pillar of salt: evidence that physical object is a sortal concept. Mind and Language, v. 12, p. 365-392, 1997. 